\title{
A market microstructure explanation of IPOs underpricing
}

\author{
Patrick L. Leoni \\ Department of Economics, National University of Ireland at Maynooth, Maynooth Co. \\ Kildare, Ireland. Phone: +353 1708 6420, e-mail: patrick.leoni@nuim.ie
}

\begin{abstract}
In a typical IPO game with first-price auctions, we argue that risk-averse investors always underbid in equilibrium because of subjective interpretations of the firm' communication about its actual value and resulting risk aversion about the likelihood of facing investors with higher valuations. We show that the noisier the investors' inferences of the firm' value (in the sense of first-order stochastic dominance) the higher the underbidding level. Our finding is independent of winner's curse effects and possible irrationality, and allows for a testable theory.
\end{abstract}

Keywords: IPO underpricing; first-price auction; risk aversion; firm' communication

JEL classification: $\mathrm{C} 7, \mathrm{D} 81, \mathrm{G} 12, \mathrm{G} 32$

\section{Introduction}

Underpricing is a common feature of Initial Public Offerings (IPOs). Two main explanations have been given so far. The first explanation stems from a winner's curse effect to compensate uninformed traders for receiving large fractions of overpriced shares (Rock, 86); the second argues that 'sentiment' or irrational traders may distort prices downward (Cornelli et al. (04) and Leite, 05).

We present a new explanation to underpricing based on the analysis of market microstructure of IPO issuance, in particular on the analysis of issuance through the most common first-price auctions (Kandel et al. (99), see also Biais and Faugeron-Crouzet (02) for other types). We argue that, in a typical IPO game with such auctions, the noisier the inferences of CARA investors about the firm' value (in the sense of first-order stochastic dominance) from the pre-issuance communication effort of the firm, the higher the underbidding level. Moreover, we show that this phenomena is independent of winner's curse effects, private information and investors' irrationality as typically argued. 
We show that CARA investors always underbid in equilibrium because of subjective interpretations of the firm' communication about its actual value and resulting risk aversion about the likelihood of facing investors with higher valuations. Thus underpricing stems from both risk aversion and firm' communication effectiveness.

Our ranking of underpicing level in terms of first-order stochastic dominance allows for a testable theory. In contrast, similar results would not obtain with, say, less common second-price auctions or with risk-neutral agents (see Maskin and Riley, 84).

\section{The model}

The model has three dates. There is one firm and $n>1$ rational investors. The value of the firm is $\theta_{0} \in[\underline{\theta}, \bar{\theta}]$, this value is private information to the firm.

At $t=0$, the firm starts an IPO in the form of a first-price auction. As in Leite (2005), we make the common albeit simplifying assumption that one share only is offered to the investors. The firm sends a public signal to the investors about $\theta_{0}$. The following is common knowledge: 1$)$ every investor $i$ believes that $\theta_{i} \in[\underline{\theta}, \bar{\theta}]$ is the actual value of the firm, drawn from a random variable with twice-differentiable cumulative distribution $G_{\theta_{0}}$ (this subjective valuation can be through reputation effect or private and partial information for instance), 2) every agent assumes that her signal is accurate, 3 ) beliefs are independent. At $t=1$, the highest bidder pays her bid and receives her share. The true value of the firm then becomes public knowledge. At $t=2$, the share can be retraded to other investors by the winner.

This timing avoids for the winner the issue of reselling the share to other investors with private values. The resale value would then depend on others' signals, leading to a common-value auction. A similar result holds in the latter case but the analysis is more cumbersome; moreover, a private-value setting rules out winner's curse effects.

Given our timing, and conditional on winning with a bid $b \geq 0$ and having a signal $\theta$, the monetary gain at $t=1$ is $\theta-b$. Every agent has a CARA utility function over such monetary gains if winning (normalized so that $u(0)=0$ ), and receives 0 if loosing. A strategy for a player is a bid function $b:[\underline{\theta}, \bar{\theta}] \rightarrow \Re_{+}$. Define now the random variable $\mathrm{r}(\mathrm{x})=\theta_{\max } \mid\left\{\theta_{\max } \leq \mathrm{x}\right\}$ where $\theta_{\max }$ is the highest valuation from all the other players, for every player by symmetry.

Theorem: Let $r$ and $\bar{r}$ be two random variables as above such that $r$ first-order stochastically dominates $\bar{r}$, with respective symmetric equilibrium strategies $b$ and $\bar{b}$. For every $\theta \in[\underline{\theta}, \bar{\theta}]$, we have that $\theta \geq \bar{b}(\theta) \geq b(\theta)$.

The above theorem can be interpreted as follows: as signals or individual interpretations about the firm value become more accurate in the sense of first-order stochastic dominance, which in turn reduces in the same sense the probability of facing investors with higher valuations, investors underbid less. 
Proof: We proceed by first deriving a closed-form solution to the game, and the result then obtains by standard arguments in stochastic dominance. Define first $F(\theta)=G^{n-1}(\theta)$ for every $\theta \in[\underline{\theta}, \bar{\theta}]$.

Existence and differentiability of a symmetric equilibrium strategy $b($.$) follows$ from an argument similar to that in Th. 2 in Maskin and Riley (84). Consider the problem of, say, Investor 1 when all the other investors play according to $b($.$) . Her bidding$ strategy $b($.$) must satisfy for every \theta \in[\underline{\theta}, \bar{\theta}]$

$$
\theta \in \operatorname{Arg} \max _{x} F(x) \cdot u(\theta-b(x)) .(=E(u))
$$

Differentiating the objective function in Eq. (1) and using optimality conditions leads to the differential equation

$$
b^{\prime}(\theta)=\frac{F^{\prime}(\theta)}{F(\theta)} \cdot \frac{u(\theta-b(\theta))}{u^{\prime}(\theta-b(\theta))},
$$

with the boundary condition $b(\underline{\theta})=\underline{\theta}$ since an investor with this signal has a zero probability of winning the auction and thus bids at her lowest level. Define now, for every $x \in[\underline{\theta}, \bar{\theta}]$, the certainty equivalent $C E(x)$ to solve

$$
u(x-C E(x))=E_{\hat{y}}[u(x-\hat{y}) \mid \hat{y} \leq x],
$$

where $\hat{y}$ is the maximum of the signals received by all the investors but Investor 1 . Since $u($.$) is CARA, C E($.) does not depend on the wealth and thus Eq. (3) rewrites as

$$
u(\theta-C E(x))=E_{\hat{y}}[u(\theta-\hat{y}) \mid \hat{y} \leq x] \text { for every } \theta .
$$

Differentiating Eq. (5) with respect to $x$, using the property of the derivatives of $u($.$) ,$ recalling that $u(0)=0$ and rearranging yields the differential equation

$$
[C E(\theta)]^{\prime} \cdot u^{\prime}(\theta-C E(x))=-\frac{F^{\prime}(\theta)}{F(\theta)} \cdot u(\theta-C E(x)) .
$$

It is also straightforward to check from Eq. (4) that $C E(\underline{\theta})=\underline{\theta}$, thus the systems described in Eq. (2) and Eq. (5) have the same initial conditions. We thus have that $b()=.C E($.$) , which in particular proves the first inequality in the Theorem.$

For some true value $\theta_{0}$, consider now the signal interpretations $r_{\theta_{0}}$ and $\bar{r}_{\theta_{0}}$ such that $r_{\theta_{0}}$ FSD $\bar{r}_{\theta_{0}}$ with respective symmetric equilibrium strategies $b$ and $\bar{b}$. Applying the definition stochastic dominance to the certainty equivalent in Eq. (4) yields the desired inequality. The proof is now complete. 


\section{Conclusion}

We have developed a market microstructure explanation of IPOs underpricing, based on bidding behavior of investors with subjective valuations stemming from firm' communication. The originality of our work is that equilibrium underpricing is not driven by winner's curse issues, but rather by interpretation of the firm' communication and resulting risk aversion about the likelihood of facing investors with higher valuations.

\section{References}

Biais, B., Faugeron-Crouzet, A.-M., 2002. IPO Auctions: English, Dutch,... French, and internet. Journal of Financial Intermediation 11, 9-36.

Cornelli, F., Goldreich, D., Ljungqvist, A., in press. Investor sentiment and pre-issue markets, Journal of Finance.

Kandell, S., Sarig, O., Wohl, A., 1999. The demand for stocks: an analysis of IPOS auctions. Review of Financial Studies 12, 227-247.

Leite, T., 2005. Returns to sentiment investors in IPOs. Economics Letters 89, 222-226.

Maskin, E, Riley, A. 1984. Optimal auctions with risk-averse buyers. Econometrica 52, 1473-1518.

Rock, K., 1986. Why new issues are underpriced. Journal of Financial Economics 15, 187-212. 